Para enlazar con este artículo / To link to this article:

http://dx.doi.org/10.14198/fem.2018.31.09

Para citar este artículo / To cite this article:

Kaiser Moro, Andrea. «El derecho al aullido: corporalidad y lenguaje en Clavícula (Sanz, 2017)». En

Feminismo/s, 31 (junio 2018): 189-203, DOI: 10.14198/fem.2018.31.09

\title{
EL DERECHO AL AULLIDO: \\ CORPORALIDAD Y LENGUAJE EN CLAVÍCULA \\ (SANZ, 2017)
}

\author{
THE RIGHT TO HOWL: \\ EMBODIMENT AND LANGUAGE IN CLAVÍCULA \\ (SANZ, 2017)
}

\author{
Andrea KAISER MORO \\ Universidad de Granada \\ orcid.org/0000-0002-2380-3733
}

\section{Resumen}

Este artículo propone un análisis del discurso de Clavícula, la novela autobiográfica de Marta Sanz publicada en 2017. En ella la escritora reflexiona sobre el dolor tras una experiencia personal donde resulta imposible diagnosticar médicamente una dolencia física. Esto permite a la escritora repensar los tópicos asociados a la salud de la mujer en los distintos ciclos de su vida. Clavícula es, así, una novela que presenta la vulnerabilidad de una mujer en crisis (social y personal) a través de la semiótica de su cuerpo.

Este trabajo es fruto de una investigación cualitativa y se apoya en herramientas conceptuales de la teoría literaria contemporánea. Se toman como referencia las reflexiones de Hélène Cixous (1995) sobre escritura femenina, así como las nociones de Byung-Chul Han en Psicopolitica (2014). Este artículo pretende identificar los aspectos por los que la propuesta de Sanz es relevante a efectos de género, reivindicando el poder del lenguaje como herramienta de autorrepresentación femenina.

Palabras clave: autobiografía, literatura contemporánea, estudios de género, escritura femenina, corporalidad. 


\begin{abstract}
This article proposes an analysis of the discourse of Clavícula, Marta Sanz's autobiographical novel published in 2017. In it, the writer reflects on pain after a personal experience where it was impossible to medically diagnose a continuous physical discomfort. This allows the writer to rethink the topics associated with the health of women in the different cycles of their lives. Clavicula is, thus, a novel that presents the vulnerability of a woman in crisis (social and personal) through the semiotics of her body.

This work is the result of qualitative research and is based on conceptual tools of contemporary literary theory. The reflections of Hélène Cixous (1995) on female writing are also taken as reference, as well as the notions of Byung-Chul Han in Psicopolitica (2014). This article aims to identify the aspects by which the proposal of Sanz is relevant to gender effects, claiming the power of language as a tool of female self-representation.
\end{abstract}

Keywords: autobiography, contemporary literature, gender studies, feminine writing, embodiment.

\title{
1. INTRODUCCIÓN
}

Recientemente la escritora Marta Sanz afirmó en una entrevista: «Escribo siempre de las cosas que me duelen». Sin interponer obstáculos entre ella y la voz narradora de su último libro, Clavícula, la madrileña defiende el regreso del texto a sí misma: "Y pasa que mucha gente, después de leer el libro, me pregunta: «¿Cómo estás?». Eso me gusta también, porque significa que el libro consigue uno de sus objetivos, que es que el lector apunte hacia la realidad, hacia lo que pasa fuera del texto» ${ }^{1}$. Clavícula no sólo es una novela autobiográfica sino que se reclama como tal: la utilización del lenguaje en esta operación no empaña el poder de notificar un dolor que señala a su autora sin diluirla en construcciones. La última novela de Sanz, publicada en marzo del pasado año tras la premiada Farándula (2015), busca reconquistar la confianza perdida en la narración biográfica. Y romper una lanza en favor de la herramienta más vilipendiada del siglo pasado: el lenguaje.

1. Ambas declaraciones han sido extraídas de una entrevista a Marta Sanz en Páginasiete (en línea). Disponible en http://www.paginasiete.bo/letrasiete/2016/9/4/marta-sanzescribo-siempre-cosas-duelen-108295.html [15-05-2017]

Feminismo/s 31, junio 2018, pp. 189-203 
Clavícula forma parte de un proyecto global donde lo autobiográfico se emplea como estrategia de afirmación personal: en este sentido, Lección de anatomía (2008) y Éramos mujeres jóvenes (2016) reelaboran la historia personal de la escritora a través de la recopilación de memorias y testimonios de mujeres de su familia «buscando un lenguaje que sea un modo de mirar y una mirada que exija un lenguaje distinto. Hablando feo de lo feo» (Sanz, Nombrar el cuerpo, conquistar el territorio 61). En ellas Sanz deconstruye los modelos hegemónicos de la autobiografía y experimenta con las fronteras entre realidad y ficción, así como entre lo ensayístico y lo poético desde el compromiso de la primera persona (Vara 2). Esto se sustenta en la concepción literaria de la propia Sanz, donde «no hay necesidad de una tercera persona. La distancia respecto a uno mismo, que nos acerca al lector, se consigue cuando la realidad personal se hace realidad del texto a través de las estrategias de manipulación lingüística con las que suscribimos un pacto con la literatura y con la vida» (Sanz, No tan incendiario 107). El yo lírico de Marta Sanz genera, así, una narración ambigua y paradójica donde la autorrepresentación de la autora se ve acompañada de la representación de la alteridad: ya se trate de sus relaciones con los otros o los aspectos inaprehensibles de su propio yo (Vara 208) siempre desde la conciencia del momento histórico y los efectos de lo político en lo personal (Somolinos 92).

\section{OBJETIVOS Y METODOLOGÍA}

Este artículo es el resultado de una investigación cualitativa y en él se han empleado herramientas procedentes de la teoría literaria y la narratología. Se ha realizado una revisión bibliográfica atendiendo a las aportaciones sobre escritura femenina de Hélène Cixous (1995), la noción de yo-piel de Didier Anzieu (1985) y las reflexiones sobre autobiografía y autoficción de Ana Casas (2013). Tampoco hemos perdido de vista las reflexiones de Byung-Chul Han (2014) por cuanto son parte directa del imaginario literario de Marta Sanz en Clavícula, así como las reflexiones de Adriana Cavarero y Judith Butler (2014) en torno a la noción de vulnerabilidad. El objetivo de este artículo es discernir qué función cumple la narración autobiográfica en la representación del dolor de una mujer. También se pretende identificar las estrategias narrativas y estéticas empleadas para efectuar dicha operación.

Feminismo/s 31, junio 2018, pp. 189-203 


\section{CLAVÍCULA, O CÓMO BAUTIZAR EL DAÑO}

A Marta Sanz le duele la clavícula y de eso trata su libro, que comienza con un peligroso descubrimiento: «Y, en la costilla, detecto una pequeña cabeza de alfiler que súbitamente se transforma en una huella de malignidad. Una fractura en la osamenta o el reflejo de una vorágine interior» (12). Nos hallamos ante un dolor con doble fondo y fronterizo que se reconoce como tal: en el umbral, signo de un mal mayor cuyo origen resulta imposible de ubicar. «¿Cuándo empieza el dolor?, ¿el primer síntoma?» (11) se pregunta la narradora al principio de la novela. Se trata, por tanto, de un dolor huérfano de nombre y de lugar: sólo sabemos que aparece y desaparece, que es intermitente y que se desliza por el pecho de su narradora. Como si tuviera vida propia y adoptara siempre la forma de un otro, el dolor es asociado con la figura de una garrapata "que atenaza el corazón» (20) pero también es presentado como «un ratoncito que cambia de tamaño y de forma dentro de su jaula» (45). A lo largo de la novela el sufrimiento de Sanz huye y se metamorfosea: así, pasa por ser jilguero, pez, agua sucia, musgo y, finalmente, un olor desagradable. Los recursos simbólicos empleados por la narradora terminan por ser impresiones reducidas a su mínima expresión: formas que huyen.

La lucha de la autora de Clavícula es el deseo de arañar la palabra: un intento de suplicar al lenguaje una alternativa a la misma medicina, que se revela incapaz de proponer un diagnóstico a la paciente. Clavícula es una novela-indagación que busca devolver al lenguaje, si no la capacidad de curación, sí su potestad elemental: el bautizo y el diagnóstico del mundo. «Yo quiero que me quiten un dolor. Que me ayuden a localizarlo. Que me extirpen del corazón el ansia poniéndole un nombre y un remedio» (30), afirma Sanz cuando las pruebas médicas a las que se somete no conducen a ninguna conclusión. En consecuencia, la narradora recupera en Clavícula el poder conjurador y calmante de la palabra: su condición de casa y no de cárcel. De este modo consigue tomar las riendas de su dolor e iniciar su propio tratamiento:

Hoy veo con toda claridad que la escritura quiere poner nombre e imponer un protocolo al caos [... ] La escritura araña la entropía como una cucharilla de café en el muro de la prisión. Amputa miembros. Identifica -para sanarlas- las lacras de la enfermedad. Es un escáner. (51) 
Pero al tiempo que Sanz se lanza a los diccionarios e intenta representar su interioridad, también constata un fracaso: la dificultad de pensar lo que no tiene nombre: «Mi dolor es... Nudo, corbata, pajarita, calambre, ausencia [...] Miro al médico al fondo de los ojos con la desesperación de una muda. No hay mentiras ni metáforas para expresar mi dolor» (61). Clavícula son los pasos en círculo de su narradora en busca de una palabra que quizá no existe y que hay que inventar. Pero también es el temor a que esta posibilidad quede fuera de su alcance. Sobre esta inestabilidad Hélène Cixous (1995) propuso su noción de escritura femenina: «El recorrido de la palabra femenina: trayecto de la niña: más lejos, a lo desconocido, por inventar» (56). El desconocimiento del dolor físico de Sanz exige la invención de nuevas fórmulas y aproximaciones, y en consecuencia también está lleno de vacilaciones y pasos en falso. Transitar por los límites del lenguaje también implica que éste se resienta de manera activa. De ahí la sensación de agonía y vacilación de la novela, arrojada al vacío de no saber nombrar el propio padecer. Sin embargo, lo más relevante de Clavícula es que no se resigna ante dicha dificultad: la novela es, ante todo, aullido y necesidad de aullido. La narradora asume que el lenguaje impone un peaje que acepta con el fin de extirpar el dolor, socializándolo:

No puedo mantener durante más tiempo el mutismo sobre un dolor que me atenaza cada vez más y se expande por mis brazos como veneno de medusa. No puedo reservarlo para mí sola [...] Tengo que compartir mi dolor y mi miedo para sacarlo de mí. (17)

La solución de Sanz es insertar su dolor en el mundo y observarlo literariamente: «Pero a nadie le puede dolor algo con un nombre tan hermoso. Clavícula. Clavicordio. Clavo. Clave. Llave. Clavija» (131). Tras coquetear con distintas posibilidades la narradora termina por llamar bósforo de Almasy a su dolor situado en la escotadura supraestenal. Aquí Sanz se apropia del término que los personajes de la película El paciente inglés (Minghella, 1996) utilizaron para designar la hendidura que se forma bajo el cuello de la mujer. En realidad Sanz ya tuvo este guiño con el film atribuyéndoselo al personaje Natalia de Miguel en una novela anterior, Farándula (2015). Bósforo de Almasy es, así, la estrategia con que Sanz se apropia del dolor y lo realiza a través de la literatura. 


\subsection{La escritura femenina}

Clavícula se desenvuelve en el espacio de escritura femenina designado por Helénè Cixous, que se caracteriza por el empleo del cuerpo como núcleo de significación: «¿Por qué hay pocos textos? Porque aún muy pocas mujeres recuperan su cuerpo. Es necesario que la mujer escriba su cuerpo, que invente la lengua inexpugnable que reviente muros de separación, clases y retóricas, reglas y códigos» (58). Así, el cuerpo de Marta Sanz se propone personaje y clave narrativa en Clavícula, siendo su padecer el centro de operaciones de la escritura. La palabra, así, se convierte en sismógrafo, en herramienta que articula el grito. Cixous lo definió de la siguiente manera: « $i$ Voz! Es también lanzarse, ese desparramiento del que nada vuelve. Exclamación, grito, ahogo, aullido, tos, vómito, música» (57). De influencia derridiana, la teórica francesa siempre buscó la disolución de las oposiciones binarias asociadas al pensamiento hegemónico patriarcal por considerarlas un reduccionismo de lo femenino. La escritura, así, se plantea como una estrategia para establecer la agencia femenina donde la mujer recupera la capacidad de auto-definirse al margen de las nociones instauradas socialmente. En este sentido, la reflexión sobre el cuerpo, el placer y el dolor físico son los intermediarios de dicha operación, en tanto que subversión y apropiación de las categorías definidas desde lo masculino. El lenguaje femenino se constituye, para Cixous, desde el reclamo de la propia sexualidad como motor de descubrimiento de la fuerza interna de la mujer.

La voz narrativa de Clavícula es, así, aullido y reivindicación de aullido: la representación de un dolor que no se enmascara bajo máscaras de ficción (en las que la autora se reconoce impostora) sino que busca articular su cauce. Por lo tanto, el discurso de Sanz no quiebra su sintaxis sino que habla desde la voz de la racionalidad. Clavícula es una auto-exploración, pausada y precisa, de la propia corporalidad:

Al escribirse, la Mujer regresará a ese cuerpo que, como mínimo, le confiscaron: ese cuerpo que convirtieron en el inquietante extraño del lugar, el enfermo o el muerto, y que, con tanta frecuencia, es el mal amigo, causa y lugar de las inhibiciones. Censurar el cuerpo es censurar, de paso, el aliento, la palabra. (Cixous 61) 
La escritura femenina se instaura en Sanz en el momento en que toma su cuerpo. Si oficialmente se espera de ella que supere su dolor fantasma (que no es cáncer ni tampoco depresión) y que se halla en el umbral de lo físico y lo mental, la escritora responderá con lo contrario. ¿Merece este dolor desconocido una novela? Para Sanz sí. Y aquí se encuentra el manifiesto de la autora: por encima de los calificativos de hipocondría y las alusiones al aburguesamiento de su dolor de las que es objeto (incluso por parte de sí misma), Sanz no duda de que este dolor debe ser dicho. Y desde el lugar incierto en que se inscribe: sin adulterarlo o engrandecerlo. El dolor de la narradora habita la incertidumbre y así debe ser formulado: «Pero hoy me rebelo. No soy una hipocondríaca. No estoy deprimida. Tengo un dolor. Una enfermedad. Lo reivindico. Me quejo» (86). El pacto autobiográfico en Clavícula se sustenta, así, en la vulnerabilidad de la escritora, que propone su fragilidad como aval de la narración en primera persona. La estructura fragmentaria de la novela delata la adaptación de esta experiencia: el cuerpo de Sanz, partido de dolor, fractura su narración ante la imposibilidad de escindir lo corporal de lo psíquico. De ahí la naturaleza fragmentaria de la novela, constituida a partir de breves reflexiones que generan un dietario.

Clavícula es, así, un compendio de anotaciones que tiene lugar en el marco de vida de Sanz: el descubrimiento del dolor, la dificultad de una vida precaria y el miedo a que la inestabilidad (ya se trate de la crisis económica o de su marido en paro) sea la norma de una vida que ahora, en plena madurez, se asoma a una nueva oscuridad:

Yo diría que mi línea de la vida sufre interferencias a partir de los cincuenta años. Ése es mi preciso cálculo adivinatorio. Mi profecía. Ahí se localiza exactamente la desaparición de mi confort físico y de mi publicitaria sensación de vivir. (16)

Y también, como telón de fondo, la palabra menopausia: «Busco y me empeño en encontrar los nombres. Nadie pronuncia la palabra menopausia. Es un tótem o un tabú» (52). Identificada de pronto como nudo y territorio sin explorar, Sanz esgrime una dura crítica contra la poca literatura que existe sobre esta fase del ciclo femenino y se propone identificar sus transformaciones: el malestar, la alteración de la sensibilidad y la pérdida de deseo. El reto consiste en vivir todo esto sin culpa: «Ahora soy una taza de loza de cintura para abajo. Me abrillanto con lejía. No quiero que me toquen. No me

Feminismo/s 31, junio 2018, pp. 189-203 
masturbo» (29). La diferencia de Clavícula como autobiografía es que su aval no descansa en el yo del autor, es decir, en la narración de memorias o en la reflexión de un sujeto (Casas 2013). La fianza de Clavícula es el cuerpo de Marta Sanz. La novela es autobiográfica porque existe una corporalidad que se afirma y grita: contra todo cartesianismo, Marta Sanz siente, luego existe. La relación conflictiva con el cuerpo se plantea desde el inicio de la novela: «Voy leyendo un libro -siempre leo alguna cosa- con el que procuro distraerme del ruido de mi propio cuerpo, que suena, grita, me habla. Estoy harta de escucharlo» (212) y se formula siempre en términos de ambivalencia: «Pienso en mi situación. En mis certezas. En la alta estima y el odio simultáneo que me inspira mi propio cuerpo» (26). Paradójicamente Sanz es consciente de la soberanía de su cuerpo, de su inmersión en el campo político y su condición de lugar de inscripción de los acontecimientos. Sin embargo, en la práctica actúa como si ninguna de estas cuestiones existiera, y es en dicha omisión de lo que ya sabe donde depura responsabilidades consigo misma:

En el fondo no estoy segura de decidir nada. Es la inercia. La fantasía de que de verdad elegimos y la culpa por no tomarnos con la debida seriedad los avisos de nuestro cuerpo. Como si pudiésemos parar cuando nos diera la gana. Hasta de eso tenemos la culpa. Tenemos la culpa de todo. (34)

Así, la búsqueda de un nombre para el dolor es también una oportunidad para pensarlo y reflexionar sobre su naturaleza. Sanz reconoce en Clavícula su subordinación a su propio cuerpo y advierte, en su genealogía, que el dolor que creyó exclusivamente interno se halla inmerso en un tejido tan personal como ajeno.

\section{EL PENSAMIENTO DE LA PIEL}

En sintonía con las consideraciones de Didier Anzieu, podemos identificar ciertas formas de pensamiento de la piel en Marta Sanz. El teórico propuso la noción de yo-piel para señalar la piel como envoltura del sujeto y su relevancia como contenedora de los procesos mentales. Anzieu atribuyó a la piel diversas funciones: individuación, sustento, protección, integración de las percepciones sensoriales y excitación sexual, entre otras. También reflexionó sobre la relación problemática de la piel de las personas depresivas: en concreto, sobre cómo muchos de sus pacientes describían su vulnerabilidad como una

Feminismo/s 31, junio 2018, pp. 189-203 
experiencia de sentirse sin piel. Para Anzieu, mientras el sujeto equilibrado piensa la piel como envoltura de protección, el sujeto depresivo siente la piel como una envoltura de sufrimiento.

Marta Sanz no está depresiva sino alerta. Su dolor es una herida física y no una alteración de su estado de ánimo. Por lo tanto, su actitud es todo lo contrario a la de un sujeto depresivo: la autora se erige sobre su dolor y busca combatirlo mediante todos los instrumentos a su alcance, ya sean palabras, anestesia, amigos, doctores, pastillas o literatura. Puede que Clavícula sea la articulación de una queja, pero también es una queja rebelde, que busca la curación desesperadamente. La autorrepresentación a través la piel es una constante estructural de la novela, que se propone como depositaria de la verdad de la narradora: «Me delatará el color de la piel o el fondo de un iris, que saldrá del ojo como una costra, para mostrar el mapa de mi recóndito mal. Mi piel expelerá un olor patológico por la cara interna de los codos y detrás de los pabellones auditivos» (19). La permeabilidad que Sanz asume entre su piel y sus afectos es absoluta: a través de ella su dolor se materializa y se expone a los demás. Así, la piel de la narradora se propone como texto y prueba de la propia existencia, que de pronto se reconoce inscrita en el mundo: «En un lunar de mi cuerpo reconozco el cosmos. La primera célula humana, el reptil que salió del charco y se convirtió en simio» (15). Y aunque la comprensión de la piel como lugar de sufrimiento también existe en la novela, el pensamiento que Sanz desarrolla tiene más que ver con la piel como herramienta de auto-conocimiento e individuación. La superficie se consagra como umbral de subjetivación, permitiendo a la narradora acceder a sí misma y conocer sus intersecciones:

Por otra parte, en un lunar de mi cuerpo que me escuece y muta veo la realidad como dentro de la bola de una pitonisa de feria, todo lo que me oprime, los rayos alfa, gamma o beta que irradian los módems portátiles y las redes wifi invisibles que atraviesan los muros y me apuñalan. (15)

Por medio de la piel Sanz se convierte en su propia guía espiritual: «Actúo como mi propia quiromántica y al mirarme la palma quemada de la mano izquierda detecto una línea de la vida que no se corta pero forma islas y triángulos escalenos» (16). El conocimiento a través de la piel es la metodología clínica de la narradora, el punto de partida de una auto-exploración interna. En consecuencia, cualquier tentativa de remedio que Sanz intente poner en 
práctica también pasará por la piel. Como si se tratara de un puente entre ella y su desgarro interior, afirma: «Entro en el cuarto de baño para pintarme los labios. Nadie sabrá nunca que he hecho un esfuerzo ímprobo. Que pintarme los labios es mi forma de sobreponerme» (37). Incluso en este simple gesto cosmético existe una negociación con la piel: una resistencia a la resignación y a la desidia. Sanz se niega a que su estado empeore sin más ni más. La narradora busca la curación trabajando la palabra y exteriorizando su dolor, pero también, en un diálogo continuo con su propia superficie.

Sanz no ha entrado aún en la menopausia pero intuye su proximidad. Su cuerpo se ha transformado y a partir de él su forma de estar en el mundo. La narradora detecta la imposibilidad de disociar el dolor físico del psíquico, y en consecuencia advierte la entrada a un nuevo estado de sí misma, dominado por la falta de control:

No es sólo una cuestión de imagen o de sequedad de piel, paulatina pobreza capilar, arañas vasculares en las mejillas, bolsas en los ojos... [...] Lo peor es que la menopausia provoca un estado de la sensibilidad que te induce a creerte vulnerable y, consecuentemente, a serlo. (29)

Si Adriana Cavarero y Judith Butler (2014) definieron la vulnerabilidad como una cuestión que se manifiesta a través de la piel, Sanz lo suscribe y lo padece. La debilidad de la narradora se expresa a través de un carrusel de síntomas cuyo denominador común, además de la experiencia dolorosa, es el rastro que dejan en la piel: el pelo se cae, su cara se descascarilla y la piel se seca, explicitando su recién adquirida debilidad. Pero no es sólo una cuestión de síntomas: hasta los remedios con que Sanz intenta enmendar su dolor se negocian a través de la piel. Clavícula es una novela que presenta la condición vulnerable de una mujer en crisis (social y personal, simultáneamente macro y micro) a través de la semiótica de su superficie.

La relación de Marta con su marido se ha transformado con los años y la narradora es bien consciente de ello: «Echo en falta el deseo de mi marido» (28) dice al principio de la novela. Sanz reconoce su falta de deseo pero sin la nostalgia con que percibe el cambio en sentido contrario: «No me da la gana de responder a estos modelos ni forzarme para estar permanentemente pizpireta y operativa» (30). Sanz se permite a sí misma no sexualizarse indefinidamente: se permite, pese al modelo ideal de mujer activa, ser una mujer no definida por el deseo y olvidar la tiranía del cuerpo:

Feminismo/s 31, junio 2018, pp. 189-203 
Yo no quiero estar funcionando artificialmente. Llega un momento en la vida en que es bueno dejar de correr. Hay que dejar de correr. Yo quiero que me dejen en paz. Que me dejen olvidarme de mi cuerpo. Para lo bueno y para lo malo. Olvidar la posibilidad de los orgasmos sucesivos, las punzadas más o menos intensas de placer, los calambres y el volver a buscar la conexión de los enchufes. Quiero olvidar la posibilidad de follar tanto y tan bien que escueza. (181)

Y aunque Sanz se sitúe y se acepte a sí misma lejos del erotismo en que en otro tiempo se supo, la piel sigue interviniendo en ella y configura sus afectos. Sanz desarrolla largas reflexiones sobre cómo, ahora, su piel demanda otras atenciones. Con firmeza comprueba como su relación amorosa no ha terminado, pues sigue demandando amor, pero también admite que su cuerpo solicita nuevas estrategias. Todas ellas tienen lugar en la piel: «He perdido las ganas y aun así padezco una exigente necesidad de amor. Quiero las atenciones que se le dan a un peluche. Ese tipo de mimos» (29). Su matrimonio se halla en plena transición al amor maduro: hecho que Sanz asume con tranquilidad y confianza, pero en cuyos detalles se detiene con asombro para constatar su propia transformación. Este significativo cambio, que pasa de la sensualidad voluptuosa de la juventud a la tibia ternura, también se negocia a través de la piel.

\section{LA RAÍZ SOCIAL DEL DOLOR}

Hacia la mitad de la novela, Marta Sanz aventura una hipótesis sobre su dolor. La narradora analiza la relación entre su vida anímica y su espacio social: su situación laboral, la irregularidad de su salario y las escasas posibilidades para su marido, que tiene más de cincuenta años y sólo consigue empleos miserables. La tensión es absoluta en un hogar que, pese ese a no contar con hijos, cae exclusivamente sobre los hombros de Marta. La narradora es consciente de esta situación e ironiza bíblicamente al respecto, como si la vida la penalizara por no sumarse al modelo de mujer hegemónico: «A lo mejor esto es un castigo por no haberme perpetuado en la carne de mi carne» (58). En consecuencia, Sanz se dedica intensamente a su trabajo, sin permitirse cualquier forma de descanso, placer u ocio. La narradora está inmersa en una lógica de producción a la que no puede poner freno y que coloniza todos los ámbitos de su vida: «La vida consiste en trabajar todo el día y culparse por 
esos momentos en que no se está trabajando» (69). Sanz se auto-explota de forma ilimitada ante la inestabilidad de su situación económica, que ni siquiera puede compartir con su marido: así, asume trabajos que no le interesan, presenta libros en los que no cree e imparte charlas por cualquier cantidad de dinero. Y vuelca su desasosiego en su diario:

Un día ya no puedo más y lloro en la consulta de una médica de urgencias. Ella me pregunta: « ¿A qué le tienes miedo?» Yo le respondo: «A estar enferma. A no poder trabajar» [...] Enfermo del miedo a enfermar y del miedo a no poder enfermar. A que se hunda el mundo. A que la enfermedad se relacione con la imposibilidad de pagar las facturas. (54)

Todas estas ideas guardan una estrecha relación con la hipótesis del filósofo surcoreano Byung-Chul Han en una de sus obras más polémicas y recientes: Psicopolítica (2014). De hecho Sanz, que sin duda conoce la propuesta de Han, enumera muchos de los síntomas que éste señaló como indicios del malestar de nuestro tiempo. Para el surcoreano, el drama de una sociedad postindustrial donde ya no existe la explotación explícita de opresores sobre oprimidos es la esclavitud a la que el ser humano se auto-somete. Según Han, el sujeto contemporáneo se explota de forma voluntaria en tanto que emprendedor, esto es, empresario de sí mismo. Contradiciendo la teoría del amo y el esclavo de Hegel, Han cuestiona la mistificación del trabajo y sostiene que en realidad no es un instrumento liberador sino que convierte al trabajador en esclavo de su productividad. De un modo muy parecido, Sanz, como empresaria de su vida y la de su marido, no puede dejar de explotarse ante la conciencia de que todo depende de ella. Así, la narradora padece físicamente las consecuencias del entramado social en el que está inscrita y que la sume en la extenuación física. En una distorsión casi monstruosa, Sanz se culpa por toparse incluso con los límites de su cuerpo: «Sufro cuando siento que se me gasta la capacidad de trabajo imprescindible para la autoexplotación, porque en la autoexplotación reside el germen de mi felicidad. No tolero mostrar debilidades en público porque el público es siempre un enemigo» (64). El problema, tal y como detecta Han, se desplaza a todo aquello que el sujeto se autoimpone tras interiorizar las demandas de la lógica capitalista. Para el filósofo esta coacción busca fomentar el rendimiento y optimizar al sujeto, convirtiéndolo en «instrumento del capital»(20). El surcoreano también 
sostiene que los sujetos de nuestro tiempo son incapaces de culpar al sistema cuando algo falla, porque antes que nada se culpan a sí mismos:

Quien fracasa en la sociedad neoliberal del rendimiento se hace a sí mismo responsable y se avergüenza, en lugar de poner en duda a la sociedad o al sistema. En esto consiste la especial inteligencia del régimen neoliberal. No deja que surja resistencia alguna contra el sistema (18).

En consecuencia, las enfermedades por excelencia del neoliberalismo no son enfermedades inmunológicas sino enfermedades mentales: la depresión, definida como enfermedad del yo, es para Han el daño más evidente ejercido por el neoliberalismo. Cualquier sujeto depresivo y extenuado, pero aun así inmerso en una lógica hiperactiva, es víctima de un psicopoder del que quizá no es consciente. Así, las reflexiones de Sanz están estrechamente ligadas con esto, especialmente cuando afirma: «Mi dolor es un fallo que no puedo permitirme. La prueba irrefutable de una inteligencia débil» (57). La narradora transita en una difícil encrucijada: aunque se niega a entender su dolor como un problema arbitrario y exclusivamente interno, no puede evitar atacarse por no resistir más en una circunstancia que también es dañina. Las contradicciones de auto-observar y analizar el dolor se hacen explícitas en la narración: pese a ser consciente de todo lo anterior, la narradora deambula entre la culpa por una situación de la que también se reconoce como víctima.

\section{CONCLUSIONES}

En su exploración autobiográfica Sanz llega a una lúcida conclusión: padece un dolor que necesita pensar en contexto, que no sólo señala a su cuerpo sino a la sociedad como matrices y perpetuadores del mismo. Sin querer negar su responsabilidad respecto a la negligente gestión de su dolor, su proceso de auto-conocimiento a través de la escritura le permite comprender que su extenuación no es fruto de la arbitrariedad ni tampoco es algo que sólo atañe a su individualidad. En su cuerpo se inscribe el miedo al futuro, la incertidumbre a una vida abyecta y la transición de su cuerpo hacia la edad madura. Su cuerpo manifiesta un dolor que es también daño: ejercido por un contexto que demanda de ella más de lo que físicamente puede asumir. Ante el fracaso de los diccionarios y la medicina, la narradora se apropia del

Feminismo/s 31, junio 2018, pp. 189-203 
lenguaje para ejercer su propia autorrepresentación, recuperando la función de la literatura como herramienta de conocimiento.

En este sentido, la respuesta de Sanz no es la pasividad a la que la filosofía de Han la condenaría: Clavícula contradice la idea de que el aislamiento del sujeto lo incapacita para la acción. Sanz padece en soledad pero no pierde de vista la necesidad de compartir, expandir y socializar un mal que sabe de muchos, afirmando tajantemente que el dolor «no es íntimo» (89). Sanz sufre aisladamente (pues la experiencia del dolor sólo le pertenece a uno) pero reivindica sin descanso las coordenadas políticas y sociales en que este padecer se inscribe y se vive: «Si hubiese tenido hijos, hoy me preocuparía un hipotético accidente de moto, un embarazo no deseado, los incipientes síntomas de una leucemia [...] Estaría, sobre todo, muy preocupada por saber dónde podrían caerse muertos mis hijos. De qué puta mierda iban a vivir» (58). En definitiva, la voz de Sanz aúlla pero no se queda en el abatimiento ni se encoge. Clavícula insiste en reivindicar el poder político de esta queja y en legitimar cualquier forma de dolor de la mujer. Clavícula habla del derecho al dolor y del dolor que no está dicho: el que necesita compartirse para realizarse y comprenderse. Para saberse inserto en el mundo. En este sentido juegan un papel fundamental las formas de dolor desconocido, que la sociedad aún no ha consensuado y que corren el peligro de no tomarse en consideración. Se trata, así, de un territorio que exige la experimentación del lenguaje y el avance en el vacío. Es, por tanto, el espacio de una escritura femenina que aún está por hacerse y decirse.

\section{REFERENCIAS BIBLIOGRÁFICAS}

Anzieu, Didier. El yo-piel. Madrid: Biblioteca Nueva, 1985.

Butler, Judith y Cavarero, Adriana. Cuerpo, memoria y representación. Adriana Cavarero y Judith Butler en diálogo. Ed. Belén Saez Tajafuerce. Barcelona: Icaria Editorial, 2014.

Casas, Ana. La autoficción. Reflexiones teóricas, Madrid: Arco Libros, 2013.

Cixous, Hélène. La risa de la medusa: Ensayos sobre la escritura. Trad. Ana María Moix. Barcelona: Anthropos, 1995.

Han, Byung-Chul. Psicopolítica: neoliberalismo y nuevas técnicas de poder, Barcelona: Herder, 2014.

Sanz, Marta. Clavícula, Barcelona: Anagrama, 2017. 
-. «Nombrar el cuerpo, conquistar el territorio». Cuadernos hispanoamericanos 772 (2014): 58-73.

—. No tan incendiario. Cáceres: Periférica, 2014.

Somolinos, Cristina. «Marta Sanz: cuerpo, escritura, ideología», Ínsula 834 (2016): 20-23.

Vara, Natalia. «Lecciones del 'yo': autobiografía, ficción y sujeto ético en Marta Sanz», RECIAL 8 (2017).

-. «El poema no soy yo: autobiografía y pecado original (según Marta Sanz y Ángeles Mora)». Mentiras verdaderas: autorreferencialidad y ficcionalidad en la poesía española contemporánea. Coord. Juan José Lanz y Natalia Vara. Sevilla: Renacimiento, 2016. 171-211. 